\title{
Sulfur Dioxide Effects on Human Atrial Action Potential: In Silico Study
}

\author{
Laura C Palacio ${ }^{1}$, Geraldine Durango ${ }^{1}$, Juan P Ugarte $^{2}$, Javier Saiz ${ }^{3}$, Catalina Tobón ${ }^{1}$ \\ ${ }^{1}$ MATBIOM, Universidad de Medellín, Medellín, Colombia \\ ${ }^{2}$ Grupo de Investigación en Modelamiento y Simulación Computacional, Universidad de San \\ Buenaventura, Medellín, Colombia \\ ${ }^{3} \mathrm{CI}^{2} \mathrm{~B}$, Universitat Politècnica de València, Valencia, Spain
}

\begin{abstract}
Exposure to air pollutants agents, like sulfur dioxide $\left(\mathrm{SO}_{2}\right)$, has significant effects on the cardiovascular system. Studies have shown that $\mathrm{SO}_{2}$ blocks $\mathrm{I}_{\mathrm{CaL}}$ and increases the $I_{N a}, I_{K 1}$ and $I_{t o}$ currents, which implies action potential duration (APD) decrease, favoring the initiation of atrial arrhythmias. This study aims to assess the effects of the $\mathrm{SO}_{2}$ at different concentrations on human atrial action potential, using computational simulation. For this, based on experimental data, we developed concentration-dependent equations to simulate the $\mathrm{SO}_{2}$ effects on the currents. They were incorporated in the Courtemanche model of human atrial cell and in a 2D model of atrial tissue. S1-S2 cross-field protocol was applied to initiate a rotor. $\mathrm{SO}_{2}$ concentrations from 0 to $100 \mu M$ were implemented. Our results are in agreement with results from non-human in vitro and in vivo studies. The $\mathrm{SO}_{2}$ causes APD shortening and loss of plateau phase in a fraction that increases as the concentration increases. In the $2 D$ model, a rotor can be generated from $50 \mu \mathrm{M}$ of $\mathrm{SO}_{2}$ concentration, showing a proarrhythmic effect.
\end{abstract}

\section{Introduction}

Air pollution is defined as the presence in the atmosphere of one or more substances in sufficient quantity to produce health alterations. Air pollution causes 4.3 million premature deaths annually [1]. Human exposure to air pollutants agents, like sulfur dioxide $\left(\mathrm{SO}_{2}\right)$, has significant effects on the cardiovascular system [2]. $\mathrm{SO}_{2}$ is an invisible gas that has a nasty, sharp smell. The main source of $\mathrm{SO}_{2}$ in the air is industrial activity that involves processing materials that contain sulfur. It causes cardiovascular diseases and cardiovascular mortality [3]. Studies have shown that $\mathrm{SO}_{2}$ blocks the L-type calcium channel $\left(\mathrm{I}_{\mathrm{CaL}}\right)$ [4], [5] and increases the sodium channel $\left(\mathrm{I}_{\mathrm{Na}}\right)$ [6], the transient outward potassium current $\left(\mathrm{I}_{\text {to }}\right)$ and the inward rectifying potassium current $\left(\mathrm{I}_{\mathrm{K} 1}\right)$ [7]. These effects could cause an action potential duration (APD) decrease, increasing the risk of initiation and maintenance of cardiovascular disease such as atrial arrhythmias. Certain types of atrial arrhythmias can be attributed to stable high-frequency spiral waves (rotors) [8].

This study aims to assess the effects of the $\mathrm{SO}_{2}$ at different concentrations on human atrial action potential and rotor generation, using computational simulation.

\section{Methods}

\subsection{Human atrial cell model}

The Courtemanche model [9] to simulate the atrial action potential was implemented. The transmembrane voltage $\left(\mathrm{V}_{\mathrm{m}}\right)$ is calculated by the equation:

$$
C_{m} \frac{d V_{m}}{d t}+I_{\text {ion }}+I_{\text {stim }}=0
$$

where $\mathrm{C}_{\mathrm{m}}$ is the specific membrane capacitance $(100 \mathrm{pF}), \mathrm{I}_{\mathrm{ion}}$ is the total ionic current that crosses the membrane, $\mathrm{I}_{\text {stim }}$ is the stimulus current.

\subsection{Models of $\mathrm{SO}_{2}$ effects on the ionic currents}


Using Hill's equation, we developed concentration-dependent equations to simulate the $\mathrm{SO}_{2}$ effects on $\mathrm{I}_{\mathrm{CaL}}, \mathrm{I}_{\mathrm{Na}}, \mathrm{I}_{\text {to }}$ and $\mathrm{I}_{\mathrm{K} 1}$. Based on an experimental study $[4,5]$, the mathematical relationship between the concentration of $\mathrm{SO}_{2}$ and the blocking of the current $\mathrm{I}_{\mathrm{CaL}}$ was:

$$
b_{\mathrm{SO}_{2} \mathrm{CaL}}=\frac{1}{1+\left(\frac{35.99}{D_{\mathrm{SO}_{2}}}\right)}
$$

Equations of the increase generated by $\mathrm{SO}_{2}$ in the $I_{\mathrm{Na}}, I_{K 1}$ and $I_{t o}$ currents were developed according to experimental studies $[6,7]$ :

$$
\begin{aligned}
e_{\mathrm{SO}_{2} \mathrm{Na}} & =\frac{0.841}{1+\left(\frac{10.97}{D_{S O_{2}}}\right)^{1.07}} \\
e_{\mathrm{SO}_{2} \mathrm{~K} 1} & =\frac{1}{1+\left(\frac{28.5}{D_{S O_{2}}}\right)} \\
e_{\mathrm{SO}_{2} t o} & =\frac{1}{1+\left(\frac{17}{D_{S O_{2}}}\right)}
\end{aligned}
$$

where $\mathrm{D}_{\mathrm{SO}_{2}}$ is the $\mathrm{SO}_{2}$ concentration in $\mu \mathrm{M}$. The factors $\left(1-b_{\mathrm{SO}_{2} \mathrm{CaL}}\right),\left(1+e_{\mathrm{SO}_{2} \mathrm{Na}}\right),\left(1+e_{\mathrm{SO}_{2} \mathrm{KI}}\right)$ and $\left(1+e_{S O_{2 t o}}\right)$ were introduced to the $\mathrm{I}_{\mathrm{CaL}}, \mathrm{I}_{\mathrm{Na}}, \mathrm{I}_{\mathrm{K} 1}$ and $\mathrm{I}_{\text {to }}$ equations in the cell model.

\subsection{D model of human atrial tissue and electrical propagation}

A 2D model of human atrial tissue was developed, it consists of a $6 \times 6 \mathrm{~cm}$ matrix, discretized at a spatial resolution of $312,5 \mu \mathrm{m}$, to form a square mesh of $192 \times 192$ elements.

The monodomain model described by the reaction-diffusion equation defined the electrical propagation of action potential in the tissue:

$\frac{1}{s_{v}} \nabla \cdot\left(D \nabla V_{m}\right)=C_{m} \frac{\delta V_{m}}{\delta t}+I_{\text {ion }}+I_{\text {stim }}$

where $\mathrm{S}_{\mathrm{v}}$ is the surface/volume ratio, $D$ is the conductivity tensor. The equation was solved using a semi-spectral scheme [10] in a program developed in MATLAB ${ }^{\circledR}$. The tissue was considered isotropic. A conductivity of 0.4 $\mathrm{S} / \mathrm{cm}$ was assigned in order to obtain a conduction velocity of $62.5 \mathrm{~cm} / \mathrm{s}$.

\subsection{Simulation protocol}

We implemented the unicellular model to simulate the atrial action potential using the Cellular Open Resource public CellML OpenCOR ${ }^{\circledR}$ software. Forward Euler method with a time step of $0.001 \mathrm{~ms}$ was implemented to solve the equations. A train of 10 stimuli was applied at a basic cycle length of $1000 \mathrm{~ms}$. The APD at $90 \%$ of the repolarization $\left(\mathrm{APD}_{90}\right)$ and the different currents were measured on the 10th beat.

The S1-S2 cross-field protocol was applied in the 2D model to initiate a rotor. The $\mathrm{S} 1$ stimulus was plane and it was applied at the left boundary of the model. The S2 stimulus was square $(3 \mathrm{~cm} \times 3 \mathrm{~cm})$ and was applied after $\mathrm{S} 1$ at a corner of the model.

$\mathrm{SO}_{2}$ concentrations from 0 to $100 \mu \mathrm{M}$ were implemented. The simulations ran for $2 \mathrm{~s}$.

\subsection{Phase singularity analysis}

The rotor tip motion is defined through phase singularity analysis. A phase map is generated by calculating the Hilbert transform of the membrane potential time series. The singularity is defined as the point where the phases, from $-\pi$ to $\pi$, converge and it is estimated through the topological charge density [11].

\section{Results}

The $\mathrm{SO}_{2}$ causes the APD shortening and loss of plateau phase of the action potential in a fraction that increases as the concentration increases (Figure 1).

For the highest $\mathrm{SO}_{2}$ concentration $(100 \mu \mathrm{M})$, the $\mathrm{I}_{\mathrm{CaL}}$ peak decreases by $63 \%$, the $\mathrm{I}_{\mathrm{Na}}, \mathrm{I}_{\text {to }}$ and $\mathrm{I}_{\mathrm{K} 1}$ peaks increases by $71 \%, 118 \%$ and $78 \%$, respectively, and the $\mathrm{APD}_{90}$ decreases by $71 \%$ (Table 1). The RMP does not show significant changes. 


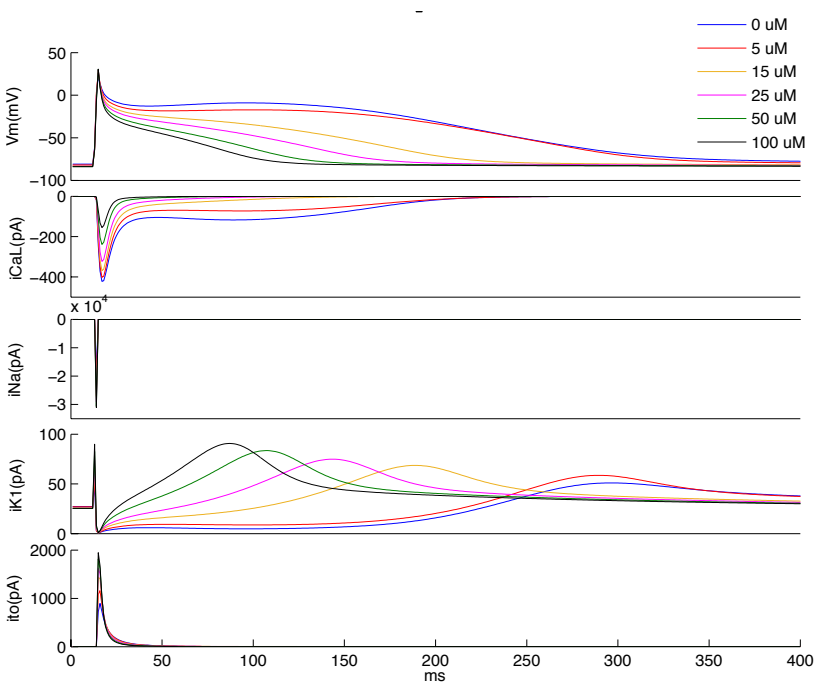

Figure 1. Action potential and $\mathrm{I}_{\mathrm{CaL}}, \mathrm{I}_{\mathrm{Na}}, \mathrm{I}_{\mathrm{K} 1}$ and $\mathrm{I}_{\text {to }}$ currents, at different concentrations of $\mathrm{SO}_{2}$.

Table 1. APD values and peaks of the currents, at different $\mathrm{SO}_{2}$ concentration.

\begin{tabular}{cccccc}
\hline $\begin{array}{c}{\left[\mathrm{SO}_{2}\right]} \\
(\mu \mathrm{M})\end{array}$ & $\begin{array}{c}\mathrm{APD} \\
(\mathrm{ms})\end{array}$ & $\begin{array}{c}\mathrm{I}_{\mathrm{CaL}} \text { peak } \\
(\mathrm{pA})\end{array}$ & $\begin{array}{c}\mathrm{I}_{\mathrm{Na}} \text { peak } \\
(\mathrm{pA})\end{array}$ & $\begin{array}{c}\mathrm{I}_{\mathrm{to}} \text { peak } \\
(\mathrm{pA})\end{array}$ & $\begin{array}{c}\mathrm{I}_{\mathrm{K} 1} \text { peak } \\
(\mathrm{pA})\end{array}$ \\
\hline 0 & 314 & -422 & -18143 & 894 & 51 \\
5 & 303 & -402 & -21965 & 1160 & 59 \\
15 & 200 & -369 & -27098 & 1439 & 69 \\
25 & 153 & -323 & -29101 & 1615 & 75 \\
50 & 115 & -239 & -30660 & 1812 & 83 \\
100 & 92 & -155 & -31091 & 1946 & 91 \\
\hline
\end{tabular}

By applying the S1-S2 cross-field protocol in the $2 \mathrm{D}$ model at $\mathrm{SO}_{2}$ concentrations of $0,5,15$, $25 \mu \mathrm{M}$, it was not possible to generate a rotor, the wavefront generated by S2 turns on itself, but it collides with its own refractory tail (inexcitable tissue) and it extinguishes, because the refractory period is greater than the turning trajectory.

On the other hand, when we applied $\mathrm{SO}_{2}$ concentrations of 50 and $100 \mu \mathrm{M}$, the wavefront (having a shorter refractory period) encounters excitable tissue and continues to turn on itself, generating a rotor in the tissue (Figure 2).

The singularity phases of the rotors indicate stable activity in both cases, where the core zones have about $0.9 \mathrm{~cm}$ of diameter.
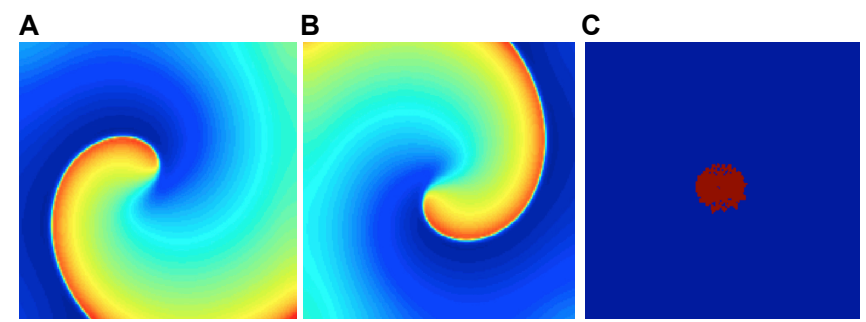

Figure 2. (A-B) Rotor and (C) the singularity phase by $\mathrm{SO}_{2}$ concentration of $50 \mu \mathrm{M}$.

\section{Discussion}

Clinical studies have shown that air pollution increases the risk of cardiovascular disease mortality by $76 \%$ [12]; such deaths are mainly related to ischemia, arrhythmias and heart failure. Sufficient evidence has been found to conclude that a brief exposure to high levels of pollutants increases the cardiac mortality. Recent studies have been able to demonstrate that cardiac arrhythmias present higher probability of occurrence after the exposure to air pollutants, thus concluding that air pollution is an acute "trigger" of these arrhythmias [13].

Our results in a human atrial cell model are in agreement with results from non-human in vitro and in vivo studies. Experimental studies in isolated rat ventricular myocytes [4]-[7] showed that exposure to $\mathrm{SO}_{2}$ derivatives causes a decrease of the $\mathrm{I}_{\mathrm{CaL}}$ current and an increase of the $\mathrm{I}_{\mathrm{Na}}, \mathrm{I}_{\text {to }}$ and $\mathrm{I}_{\mathrm{K} 1}$ currents, in a greater fraction as the concentration increases, which can produce damage in cardiomyocytes and result in hypoxia and ischemia.

Our results are consistent with these studies; when the concentration of $\mathrm{SO}_{2}$ increases, the APD decreases, which is a proarrhythmic effect. When the APD decreases the refractory period it is also shortened, causing that spiral wave encounters excitable tissue and continues to turn on itself, generating a rotor. At the inner tip of the spiral wave, the source-sink relationship is critical and excitation fails. The failure to excite the central zone produces a region of excitable, but non-excited, tissue within the rotating spiral wave called the 'core'. Anchoring at this zone stabilizes the rotor. Reduced $\mathrm{I}_{\mathrm{CaL}}$ and increased 
$\mathrm{I}_{\mathrm{K} 1}$ accelerate and stabilize rotors by abbreviating APD and refractory period [14]. The singularity phases shown in our results indicate stable activity of the rotors generated by applying $\mathrm{SO}_{2}$ concentrations of 50 and 100 $\mu \mathrm{M}$.

There are no in silico studies of the effects of $\mathrm{SO}_{2}$ on human atrial action potential. Despite the existence of studies of the effects of air pollutants on the cardiovascular system in the literature, the mechanisms underlying the effects of acute and chronic exposure to these agents on the heart have not been well established. In silico studies may contribute to a better understanding of the mechanisms by which air pollutants have unhealthy effects on cardiac tissue, promoting cardiac diseases such as arrhythmias.

\section{Conclusion}

Our results show pro-arrhythmic effects of $\mathrm{SO}_{2}$ expressed through APD shortening and a rotor generation, during normal electrophysiological conditions.

\section{Acknowledgements}

This work was supported by the "Departamento Administrativo de Ciencia, Tecnología e Innovación - Colciencias" of Colombia; and the "Dirección General de Política Científica de la Generalitat Valenciana" of Spain (PROMETEU2016/088).

\section{References}

[1] OECD. The cost of air pollution: health impacts of road transport. Paris: OECD Publishing, 2014.

[2] Zhang Q, Tian J, Bai Y, et al. Effects of sulfur dioxide and its derivatives on the functions of rat hearts and their mechanisms. Procedia Environ. Sci. 2013;18:43-50.

[3] U.S. Environmental Protection Agency. Air quality planning \& standards, 2015. [Online]. Available: https://www3.epa.gov/airquality/. [Accessed: 01-May2017].

[4] Nie A, Meng Z. Modulation of L-type calcium current in rat cardiac myocytes by sulfur dioxide derivatives. Food Chem. Toxicol. 2006;44(3):355-63.

[5] Zhang RY, Du JB, Sun Y, et al. Sulfur dioxide derivatives depress L-type calcium channel in rat cardiomyocytes. Clin. Exp. Pharmacol. Physiol. 2011;38(7):416-22.

[6] Nie A, Meng Z. Study of the interaction of sulfur dioxide derivative with cardiac sodium channel. Biochim. Biophys. Acta. 2005;1718(1-2):67-73.

[7] Nie A, Meng Z. Sulfur dioxide derivative modulation of potassium channels in rat ventricular myocytes. Arch. Biochem. Biophys. 2005;442(2):187-95.

[8] Nattel S, Xiong F, Aguilar M. Demystifying rotors and their place in clinical translation of atrial fibrillation mechanisms. Nature Reviews Cardiology 2017;14(9):509-20.

[9] Courtemanche M, Ramirez RJ, Nattel S. Ionic mechanisms underlying human atrial action potential properties: insights from a mathematical model. Am. J. Physiol. 1998;275:H301-21.

[10] Ugarte J, Tobón C, Orozco-Duque A, et al. Generation of fibrillatory dynamics in cardiac tissue: fractional diffusion as arrhythmogenic mechanism modelling tool. Appl. Math. Sci. 2017;11(13):637-50.

[11] Bray MA, Lin SF, Aliev RR, et al. Experimental and theoretical analysis of phase singularity dynamics in cardiac tissue. J. Cardiovasc. Electrophysiol. 2001;12(6):716-22.

[12] Miller KA, Siscovick DS, Sheppard L, et al. Long-term exposure to air pollution and incidence. N. Engl. J. Med. 2007;356(5):447-58.

[13] Link MS, Luttmann-Gibson H, Schwartz J, et al. Acute exposure to air pollution triggers atrial fibrillation. J. Am. Coll. Cardiol. 2013;62(9):816-25.

[14] Pandit SV, Berenfeld O, Anumonwo JMB, et al. Ionic determinants of functional reentry in a 2-d model of human atrial cells during simulated chronic atrial fibrillation. Biophys. J. 2005;88(6):3806-21.

Address for correspondence.

Catalina Tobón Zuluaga

Universidad de Medellín, Bloque 5, Oficina 111.

Carrera $87 \mathrm{~N}^{\circ} 30-65$, Medellín, Colombia

ctobon@udem.edu.co 